\title{
Controlled-release codeine is equivalent to aceta- minophen plus codeine for post-cholecystectomy analgesia
}

\author{
[La codéine à libération contrôlée est équivalente à de l'acétaminophène plus de la \\ codéine pour l'analgésie postcholécystectomie]
}

Frances Chung MD, ${ }^{*}$ Doris Tong MD, ${ }^{*}$ Paula C. Miceli Msc, $\dagger$ Joseph Reiz Bsc, $†$ Zoltan Harsanyi MBA, $\dagger$ Andrew C. Darke PhD,$\dagger$ Lance W. Payne PHARMD $†$

Purpose: Following ambulatory surgery, long-acting analgesics may provide advantages over short-acting analgesics. This study compared controlled-release codeine (CC) and acetaminophen plus codeine (A/C; $300 \mathrm{mg} / 30 \mathrm{mg}$ ) for pain control in the 48-hr period following laparoscopic cholecystectomy.

Methods: Eligible patients were randomized to $C C$ or $A / C$ in a double-blind, double-dummy parallel group study. Unrelieved pain in hospital was treated with fentanyl iv bolus. Pain [100 mm visual analogue scale (VAS)] was assessed before the first dose of medication; at 0.5 , one, two, three, and four hours post-dose; at discharge; and three times a day for $48 \mathrm{hr}$. Adverse events were recorded and measures of patient satisfaction were assessed at the end of the study.

Results: Eighty-four patients were enrolled in the study; 42 patients in each group. There were no statistically significant differences between $C C$ and $A / C$ treatment. Mean VAS baseline pain was similar in both groups $(P=0.49)$ and there was no significant difference in the time to onset of analgesia $(P=0.17)$. At $0.5 \mathrm{hr}$, the mean VAS pain score was significantly reduced from baseline in both groups $(P=0.0001)$. The VAS pain scores at discharge were reduced $59 \%$ and $56 \%$ from baseline, respectively $(P=0.61)$. There was no difference between treatments in the incidence of adverse events and patients reported similar levels of satisfaction.

Conclusions: Controlled-release codeine provides an equivalent onset of analgesia, reduction in postoperative pain, and level of patient satisfaction, to acetaminophen plus codeine, over $48 \mathrm{hr}$ following cholecystectomy, with the advantage of less frequent dosing.
Objectif : En chirurgie ambulatoire, les analgésiques postopératoires d'action prolongée peuvent avoir des avantages sur les analgésiques d'action brève. Nous comparons la codéine à libération contrôlée (CC) et une combinaison d'acétaminophène et de codéine (A/C; 300 $\mathrm{mg} / 30 \mathrm{mg}$ ) comme analgésique pendant $48 \mathrm{~h}$ après une cholécystectomie laparoscopique.

Méthode : Des patients admissibles à l'expérimentation ont reçu de la CC ou de l'A/C lors d'une étude à double insu, à double placebo en contrôle parallèle. À l'hôpital, la douleur tenace a été traitée avec des bolus iv de fentanyl. La douleur [échelle visuelle analogique (EVA) de $100 \mathrm{~mm}$ ] a été évaluée avant la première dose de médicament ; à 0,5 , une, deux, trois et quatre heures après la dose ; au moment du départ et trois fois par jour pendant $48 \mathrm{~h}$. Les événements indésirables ont été notés et des mesures de la satisfaction du patient ont été faites à la fin de l'étude.

Résultats : L'étude a été réalisée auprès de 84 patients : 42 dans chaque groupe. II n'y a pas eu de différence statistiquement significative entre les traitements à la CC ou à l'A/C. La douleur initiale moyenne a été similaire dans les deux groupes $(P=0,49)$ et il n'y a pas eu de différence significative de temps précédant le début de l'analgésie $(P=0,17)$. À $0,5 \mathrm{~h}$, le score de douleur moyen à l'EVA était significativement réduit dans les deux groupes $(P=0,000 \mathrm{l})$. Les scores à l'EVA au départ de l'hôpital ont été respectivement réduits de $59 \%$ et de $56 \%$ par rapport aux mesures initiales de la douleur ( $P$ $=0,61)$. Aucune différence intergroupe dans l'incidence d'événements indésirables n'a été notée et la satisfaction des patients était comparable d'un groupe à l'autre.

Conclusion : La codéine à libération contrôlée offre un délai d'installation de l'analgésie, une réduction de la douleur postopératoire et un niveau de satisfaction équivalents à une combinaison d'acétaminophène et de codéine pendant 48 h après une cholécystectomie, et ce, avec l'avantage d'un dosage moins fréquent.

From the Department of Anesthesia, ${ }^{*}$ Toronto Western Hospital, University of Toronto, Toronto; and Purdue Pharma, $\uparrow$ Pickering, Ontario, Canada. Address correspondence to: Dr. Frances Chung, Department of Anesthesia, Toronto Western Hospital, 399 Bathurst Street, Toronto,

Ontario M5T 2S8, Canada. Phone: 416-603-5118; Fax: 416-603-6494; E-mail: frances.chung@uhn.on.ca

This study was partially supported by a grant from Purdue Pharma (Canada) Inc.

Accepted for publication May 29, 2003.

Revision accepted December 1, 2003. 


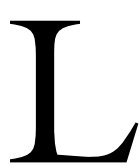

APAROSCOPIC cholecystectomy is the surgical treatment of choice for symptomatic cholecystolithiasis and can be used in more than $90 \%$ of cases. ${ }^{1,2}$ Over 37,000 laparoscopic cholecystectomy procedures were performed in Canadian facilities during the fiscal year 2000-2001. ${ }^{3}$ The laparoscopic approach to cholecystectomy has shortened the in-hospital recovery period following surgery from one to three days to same-day discharge. ${ }^{4,5}$ Discharge time is dependent, in part, on the rate of recovery from anesthesia and the provision of appropriate postoperative analgesia., ${ }^{6,7}$ Unanticipated admissions due to inadequate pain have enormous medical, social and cost implications. ${ }^{7}$ Therefore, the aim of an analgesic technique should be not only to reduce post-laparoscopic pain, but also to facilitate earlier mobilization, reduce perioperative complications, and increase patient satisfaction. ${ }^{7}$

Following laparoscopic cholecystectomy, patients tend to report parietal, ${ }^{8}$ visceral $^{9}$ and shoulder pain. ${ }^{10,11}$ Visceral pain is predominant during the first few postoperative hours. The major groups of drugs used in the treatment of postoperative pain are opioid analgesics, ${ }^{12-15}$ and non-steroidal anti-inflammatory drugs. ${ }^{7}$ Moderate to severe pain may follow laparoscopic cholecystectomy and often necessitates the use of opioid analgesics. ${ }^{7}$ Opioids may be administered by a variety of routes; oral dosing is usually the most convenient and least expensive. It is appropriate as soon as the patient can tolerate oral intake and is the mainstay of pain management in the ambulatory surgical population. ${ }^{16}$

Since the most severe pain following laparoscopic cholecystectomy occurs during the first two to three hours, ${ }^{17,18}$ an oral opioid analgesic with an onset of less than one hour would offer an effective method of analgesia. Although oral administration is associated with a slower onset of analgesia, the duration of pain relief is significantly longer than with an equi-analgesic dose of parenteral opioid. ${ }^{7}$

Codeine plus acetaminophen combination preparations are the most commonly used opioid analgesics for ambulatory surgery procedures. ${ }^{19}$ With fixed-dose combinations of acetaminophen plus codeine there is a relatively flat dose-response curve and a clear ceiling effect and the analgesic potential of fixed-dose combinations is generally limited by unacceptable side effects associated with the acetaminophen component. Fixed-dose combination preparations must be given every four to six hours and a delay in administration, especially when ordered on a "as needed (prn)" basis, may result in lower plasma opioid concentrations and, thus, the re-emergence of pain. ${ }^{20}$

Codeine Contin ${ }^{\circledR}$ (Purdue Pharma, Pickering, $\mathrm{ON}$, Canada) is a single-entity codeine preparation available as 50, 100, 150 and $200 \mathrm{mg}$ controlledrelease tablets, which is designed to provide controlled delivery of codeine over a 12 -hr period. It is currently the only controlled-release opioid marketed in Canada for the treatment of mild to moderate pain. The controlled-release formulation has demonstrated equivalent bioavailability to immediate-release tablet or liquid codeine formulations in single dose and steady-state studies. ${ }^{21}$ In acute pain models, the median time to onset of analgesia with controlled-release codeine was 30 to $40 \mathrm{~min}$, similar to immediaterelease preparations.

Following ambulatory surgery, long-acting analgesics may have advantages compared to short-acting analgesics. The study was designed to evaluate the efficacy, safety and benefits of controlled-release codeine compared with acetaminophen plus codeine in the control of postoperative pain following laparoscopic cholecystectomy.

\section{Methods}

The study was conducted at the day surgery unit (DSU), Toronto Western Hospital. Male and female patients ( $\geq 18 \mathrm{yr}$ ) scheduled to undergo laparoscopic cholecystectomy were eligible for enrollment. Both the general and local anesthesia during the procedure were standardized for all patients.

Study patients were admitted to the postanesthetic care unit (PACU) following surgery and later transferred to the DSU for complete recovery before being discharged home. When patients reported a visual analogue scale (VAS) pain intensity $>40 \mathrm{~mm}$, but were still unable to tolerate oral analgesics, fentanyl $(12.5-50 \mu \mathrm{g}) i v$ boluses were given to titrate to a VAS $\leq 40 \mathrm{~mm}$. Patients who satisfied the PACU discharge criteria (Aldrete score $\geq 9$ ), ${ }^{22,23}$ were discharged to the DSU, where they were monitored for a short time and subsequently, discharged from hospital.

Postoperative oral analgesics were initiated when the patient was able to tolerate oral medication and when VAS $\geq 40 \mathrm{~mm}$ was reported. Patients were randomized to receive either active controlled-release codeine (CC) every $12 \mathrm{hr}$ or active acetaminophen plus codeine (A/C; $300 \mathrm{mg} / 30 \mathrm{mg}$ ) every six hours during the 48hr study period. Study blinding was maintained using the double-dummy technique, with matching placebo. All patients were administered study medication according to a structured dose de-escalation schedule: day one: CC $150 \mathrm{mg}$ every $12 \mathrm{hr}$ or A/C two tablets every six hours and day two: CC $100 \mathrm{mg}$ every $12 \mathrm{hr}$ or A/C 1 tablet every six hours. Patients who reported uncontrolled pain (VAS $\geq 40 \mathrm{~mm}$ ) following the appropriate dose of study medication while in-hospital were 
administered rescue medication in the form of fentanyl (12.5-50 $\mu \mathrm{g}$ iv bolus). No opioids other than the test medication and rescue medication were administered once the patient received the first dose of study medication. Patients who reported pain uncontrolled by the investigational study medication and rescue medication were withdrawn from the study and provided alternative treatment.

Pain intensity was assessed at 0.5 , one, two, three, and four hours, at discharge and three times a day (7-9 a.m., l-3 p.m. and 7-9 p.m.) using a $100 \mathrm{~mm}$ VAS, and a five-point categorical pain intensity scale. Baseline pain intensity was designated as the first assessment of pain intensity $\geq 40 \mathrm{~mm}$ indicated by a patient who was able to tolerate oral analgesics. The extent of pain relief was also rated on a five-point categorical scale. At the end of the study, the study investigator evaluated the overall level of pain relief experienced by the patient on a four-point categorical scale and patients were asked to complete the brief pain inventory (BPI) - short form. ${ }^{24}$

Study patients completed three measures of patient satisfaction at the end of the study period: the level of satisfaction, willingness to use the same type of medication in the future and willingness to recommend this medication to someone else.

Adverse events were collected during scheduled visits and in the daily diary, categorized by intensity (mild, moderate or severe) and the likelihood of a causal relationship to the study medication was documented. Patients were withdrawn at any time if considered medically necessary or upon patient request.

A sample size calculation of a minimum of 35 patients per treatment group was based on detecting a $10 \mathrm{~mm}$ VAS difference between treatments, accounting for baseline pain, along with the assumption of a type I error rate of 0.05 and type II error of $20(80 \%)$ power for testing a two-tailed hypothesis. The efficacy analysis included all patients who had received at least one dose of study medication and did not receive parenteral rescue medication for at least one hour following the first dose of study medication - in order to evaluate the onset of the oral preparations; all patients randomized to treatment were assessed for safety. Demographic data were compared by treatment using descriptive statistics. Daily mean pain intensity scores (VAS, categorical) and daily mean pain relief scores were compared by treatment using multivariate repeated measures analysis of variance. Overall scores were compared with analysis of covariance using baseline pain intensity (pain intensity prior to first study medication dose) as the covariate. While in hospital, patients receiving rescue medication had their pain intensity and pain relief scores at the time of rescue carried forward for one hour, the appropriate time interval of analgesia afforded by the rescue medication. For the first four-hour period in the study, the following additional pain assessment scores were derived for each patient: pain intensity difference, sum of pain intensity difference, sum of ordinal pain relief and were compared by treatment using analysis of covariance with baseline pain intensity as the covariate. The time to onset of analgesia was defined as the first time point at which a non-zero ordinal pain relief score occurred. The number of doses of rescue fentanyl were compared using the Kruskal-Wallis test. The occurrence of adverse events was compared by treatment using Fisher's exact test. The BPI scores were compared by repeated measures analysis of variance by day and overall scores were compared by analysis of covariance. Patient global satisfaction ratings, intention to return, intention to recommend, and physician's overall pain relief rating were compared by treatment using the Cochrane-Mantel-Haenzel test.

\section{Results}

Eighty-four patients were enrolled in the study; 42 patients in each group. Sixty-nine patients were evaluable for efficacy and safety; 33 in the CC group and 36 in the $\mathrm{A} / \mathrm{C}$ group. The mean age in the $\mathrm{CC}$ group was $48.9 \pm 14.2$ and $47.5 \pm 16.5 \mathrm{yr}$ in the $\mathrm{A} / \mathrm{C}$ group. The $\mathrm{CC}$ and $\mathrm{A} / \mathrm{C}$ groups were similar with respect to other demographic and clinical characteristics. For completed patients, three patients voluntarily withdrew due to lack of pain following at least one dose of CC; two patients were lost to follow-up; two patients withdrew due to adverse events and two patients withdrew due to inadequate pain control in the CC group. In the $\mathrm{A} / \mathrm{C}$ group, one patient voluntarily withdrew due to lack of pain following at least one dose of A/C; four patients withdrew due to inadequate pain control; one patient was lost to follow-up, and one patient withdrew due to adverse events.

While in hospital, three patients in the CC group and five patients in the $\mathrm{A} / \mathrm{C}$ group required fentanyl rescue. The mean daily dose $(\mu \mathrm{g})$ of fentanyl rescue during the $\mathrm{CC}$ and $\mathrm{A} / \mathrm{C}$ treatment was $2.3 \pm 7.3$ and $5.7 \pm 16.9$, respectively $(P=0.4464)$. The median number of doses of rescue fentanyl taken per day for $\mathrm{CC}$ and $\mathrm{A} / \mathrm{C}$ were 0 (range $0-1$ ) and 0 (range 0-2), respectively $(P=0.4957)$.

The mean VAS baseline pain intensities (prior to taking study medication) were $53.8 \pm 10.3$ and $55.8 \pm$ 13.1 for CC and A/C, respectively $(P=0.4919)$. The Figure shows the mean daily VAS pain intensity scores over the $48 \mathrm{hr}$ evaluation period. The mean VAS pain intensity at one-half hour following the first dose was 


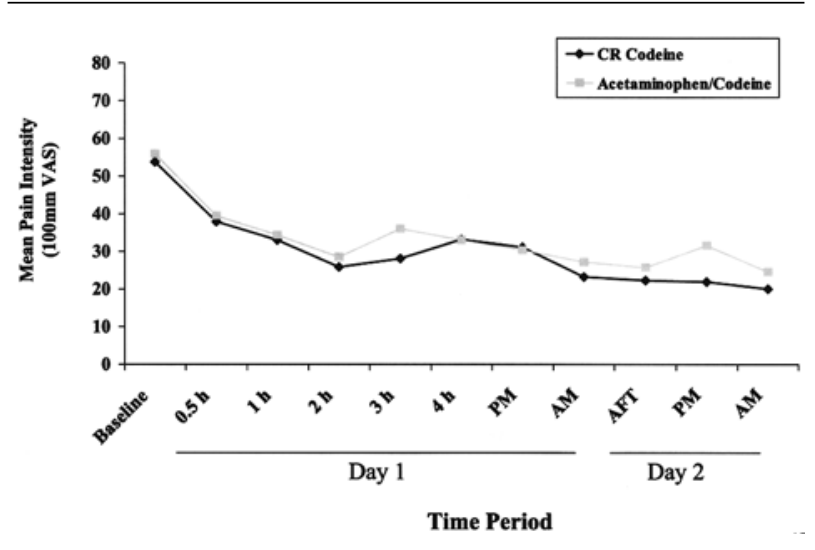

FIGURE Mean visual analogue scale (VAS) pain intensity.

significantly reduced from baseline in both groups $(P$ $=0.0001)$ and there was no difference between the two treatments (CC: $29.5 \%$ and A/C: $29.4 \%, P=$ $0.7439)$. The difference from baseline at one, two, three, and four hours post dose was also statistically significant for both treatments. The VAS pain scores at discharge were reduced $59 \%$ and $56 \%$ from baseline, respectively $(P=0.61)$. Discharge times were similar in the two treatment groups. None of the patients were readmitted following discharge from hospital.

The time of onset was defined as the first assessment time for which a non-zero pain relief score was recorded. The mean onset times for $\mathrm{CC}$ and $\mathrm{A} / \mathrm{C}$ treatment groups were $0.5 \pm 0.0$ and $0.5 \pm 0.10 \mathrm{hr}$, respectively $(P=0.17)$.

The BPI was completed at the end of the $48-\mathrm{hr}$ study period. Patients reported similar levels of pain intensity and functionality (with activities of daily living) on composite scales (pain: $P=0.4344$ and function: $P=0.6564$ ).

Global ratings of patient satisfaction showed similar levels of satisfaction for both groups (CC: $2.4 \pm 0.8$, A/C: $2.2 \pm 0.9, P=0.4664)$ and intention for future use and recommendation of the two treatments were also similar, $P=0.9515$ and $P=0.6565$, respectively. At least moderate satisfaction was reported with CC by $88 \%$ of patients, compared to $72 \%$ of patients receiving $\mathrm{A} / \mathrm{C}(P=0.17)$.

The most common adverse events reported by patients were nausea, dizziness, constipation, emesis and pruritus. There was no difference between treatments in the incidence of adverse effects. There were three serious adverse events reported in the study. In the CC treatment group, one patient, initially considered to be a candidate for same-day surgery, had failed to report a pre-existing condition of sleep apnea, which necessitated an overnight stay following the surgery. In the $\mathrm{A} / \mathrm{C}$ treatment group, two patients reported adverse events. One patient developed a postoperative ileus, which was treated and the patient fully recovered. The second patient was hospitalized due to uncontrolled pain due to stones in the common bile duct. An endoscopic retrograde cholangiopancreatography was performed and the patient fully recovered.

\section{Discussion}

Ambulatory surgery accounts for a large and everincreasing share of surgical procedures. The goal of ambulatory surgery is to provide efficient care of high quality, both during the preoperative and perioperative periods. Unanticipated readmission following same-day discharge is a significant complication and pain is a significant predictor. ${ }^{25,26} \mathrm{~A}$ recent study has shown that the best predictor of severe pain at home in day surgery patients was inadequate pain control during the first few hours following the surgery. ${ }^{19} \mathrm{~A}$ further complication may be due to the failure of patients to use pain medication as needed. Beauregard et al. (1998) reported that $32 \%$ of day surgery patients did not take any pain medication during the first $24 \mathrm{hr}$ following discharge. ${ }^{19}$ The most common concerns patients had about using pain medication were fear of drug addiction and side effects. Patients expressed the same concerns about taking their opioid analgesics in an ambulatory surgery study by Reuben et al. (1999). ${ }^{20}$ These issues highlight the importance for health-care providers to discuss issues about opioid use, such as clarifying the low risk of addiction, and to provide clear and explicit instructions to patients about the schedule of their pain medication and management of side effects.

Postoperative pain is one of the main postoperative adverse outcomes that causes distress to patients and can have a deteriorative effect on the recovery of the patient. ${ }^{27}$ Bisgaard et al. (2001) studied limiting factors for convalescence after uncomplicated laparoscopic cholecystectomy and recommended that improved pain relief may further reduce convalescence. ${ }^{28}$ These data strongly suggest that there is a need for adequate analgesia in the early postoperative period, and continued analgesia over several days following surgery using easy-to-follow dosage regimens to facilitate use of pain medication.

Opioid analgesics are the cornerstone of pharmacological postoperative pain management, especially for 
surgical procedures that cause moderate to severe pain. Opioids may be administered by a variety of routes; oral dosing is usually the most convenient and least expensive route of administration. It is appropriate as soon as the patient can tolerate oral intake and is the mainstay of pain management in the ambulatory surgical population. ${ }^{16}$

Controlled-release codeine has been shown to provide similar levels of analgesia compared to immediate-release codeine preparations. A perceived issue by clinicians about the use of controlled-release opioids for shorter-term pain is that the onset of analgesia is substantially slower than immediate-release preparations. This study confirmed previous research demonstrating that the mean onset of pain relief with this formulation of controlled-release codeine occurs within one hour of initial dosing, which is similar to the onset for acetaminophen/codeine combination preparations. A prompt onset of analgesia, similar to immediate-release preparations, has also been demonstrated for controlled-release oxycodone. ${ }^{29,30}$ This profile suggests that controlled-release codeine or oxycodone may be useful in the treatment of pain caused by acute traumatic injuries lasting a few days or more.

All patients experienced a significant reduction in their pain scores from baseline at one half-hour postfirst dose ( $-30 \%$ of baseline for CC and A/C groups), which continued to decline over the next four hours. Patients reported a stepwise reduction in pain intensity over the $48 \mathrm{hr}$ study period. The use of rescue medication prior to discharge from PACU was low (CC: $7 \%$ and $\mathrm{A} / \mathrm{C}$ : $12 \%)$. At discharge, patients reported an overall decrease in their pain scores of approximately $59 \%$ for controlled-release codeine and $56 \%$ for acetaminophen plus codeine compared with baseline. Furthermore, on average, patients reported pain intensity levels below $40 \mathrm{~mm}$ from the time of the first half-hour assessment until the end of the 48-hr study period. Controlled-release codeine was well tolerated by the patients, who experienced typical opioid-related adverse events.

The results of this study suggest that the fixed dose de-escalation ( $150 \mathrm{mg}$ every $12 \mathrm{hr}$ controlled-release codeine day one; $100 \mathrm{mg}$ every $12 \mathrm{hr}$ controlledrelease codeine day two) provided adequate pain control during the postoperative period for most patients. There was a significant reduction in pain intensity during the early postoperative period with controlledrelease codeine $150 \mathrm{mg}$ every $12 \mathrm{hr}$ that was similar to treatment with acetaminophen plus codeine preparations. Although the dosage of controlled-release codeine was decreased from $150 \mathrm{mg}$ every $12 \mathrm{hr}$ to $100 \mathrm{mg}$ every $12 \mathrm{hr}$ on postoperative day two, patients continued to report levels of pain intensity below 40 $\mathrm{mm}$ and did not require hospital readmission or study withdrawal for unrelieved pain. These data suggest that the dose de-escalation utilized in this study was appropriate and provided adequate analgesia. Similarly a tapering dose of controlled-release oxycodone in patients undergoing outpatient anterior cruciate ligament surgery has been shown to improve postoperative sleep patterns and overall analgesic efficacy compared to shorter-acting opioid analgesic preparations. ${ }^{20}$ Use of controlled-release opioids, in combination with local anesthetic infiltration and adjuvant agents, has been suggested for the management of severe postoperative pain in patients undergoing more involved surgical procedures, patients undergoing more painful procedures, or those patients who might otherwise be expected to have a high postoperative opioid dose requirement. ${ }^{31}$

The potential advantages of controlled-release codeine compared to immediate-release preparations in the treatment of acute pain include an extended duration of action, more uniform plasma concentrations and clinical effects, a reduced dosing frequency with greater convenience, improved compliance, and uninterrupted night-time sleep, thereby providing the potential for more effective continuous postoperative analgesia.

The results of this study demonstrate that controlled-release codeine given every $12 \mathrm{hr}$ is effective in the treatment of postoperative pain following laparoscopic cholecystectomy. Considering earlier reports of the propensity for patients to use significantly less medication than may be required to relieve pain when taking short-acting preparations on a as-needed basis, ${ }^{19}$ a twice daily controlled-release single entity opioid may be a valuable analgesic to improve compliance, and therefore facilitate greater levels of pain control.

Postoperative pain in ambulatory surgical patients in the hospital and at home should not be underestimated. New analgesic techniques, such as the use of controlled-release opioids, that are effective and do not increase the incidence of postoperative adverse outcomes should be considered.

\section{References}

1 Cuschieri A. Laparoscopic cholecystectomy: indications, technique and results, pros and cons. Dig Surg 1991; 8: 104-7.

2 Jakimowicz JJ. Cholecystectomy - the 'golden standard' treatment for cholecystolithiasis: the evolution of surgical technique. Dig Surg 1991; 8: 71-5.

3 Hospital Morbidity Database, Canadian Institute for Health Information (CIHI). Ontario Ministry of Health, 2002. 
4 Anonymous. A prospective analysis of 1518 laparoscopic cholecystectomies. The Southern Surgeons Club. N Engl J Med 1991; 324: 1073-8.

5 Berci G, Sackier JM. The Los Angeles experience with laparoscopic cholecystectomy. Am J Surg 1991; 161: 382-4.

6 Michaloliakou C, Chung F, Sharma S. Preoperative multimodal analgesia facilitates recovery after ambulatory laparoscopic cholecystectomy. Anesth Analg 1996; 82: 44-51.

7 Joshi GP. Postoperative pain management. Int Anesthesiol Clin 1994; 32: 113-26.

8 Joris J, Thiry E, Paris P, Weerts J, Lamy M. Pain after laparoscopic cholecystectomy: characteristics and effect of intraperitoneal bupivacaine. Anesth Analg 1995; 81: 379-84.

9 Joris J, Cigarini I, Legrand M, et al. Metabolic and respiratory changes after cholecystectomy performed via laparotomy or laparoscopy. Br J Anaesth 1992; 69: 341-5.

10 Collins KM, Docherty PW, Plantevin OM. Postoperative morbidity following gynaecological outpatient laparoscopy. A reappraisal of the service. Anaesthesia 1984; 39: 819-22.

11 Edwards ND, Barclay K, Catling SJ, Martin DG, Morgan RH. Day case laparoscopy: a survey of postoperative pain and an assessment of the value of diclofenac. Anaesthesia 1991; 46: 1077-80.

12 Graf DF, Pandit SK, Kothary SP, Freeland GR. A double-blind comparison of orally administered ciramadol and codeine for relief of postoperative pain. J Clin Pharmacol 1985; 25: 590-5.

13 Brunelle RL, George RE, Sunshine A, Hammonds WD. Analgesic effect of picenadol, codeine, and placebo in patients with postoperative pain. Clin Pharmacol Ther 1988; 43: 663-7.

14 Gertzbein SD, Tile M, McMurty RY, et al. Analysis of the analgesic efficacy of acetaminophen $1000 \mathrm{mg}$, codeine phosphate $60 \mathrm{mg}$, and the combination of acetaminophen $1000 \mathrm{mg}$ and codeine phosphate 60 $\mathrm{mg}$ in the relief of postoperative pain.

Pharmacotherapy 1986; 6: 104-7.

15 Forbes JA, Bates JA, Edquist IA, et al. Evaluation of two opioid-acetaminophen combinations and placebo in postoperative oral surgery pain. Pharmacotherapy 1994; 14: 139-46.

16 Acute Pain Management Guideline Panel. Acute Pain Management: Operative or Medical Procedures and Trauma. Clinical Practice Guidelines. AHCPR Pub No. 92-0032, Rockville, MD: Agency for Health Care Policy and Research, Public Health Service. U.S. Department of Health and Human Services. February 1992.
17 Narchi P, Benhamou D, Fernandez H. Intraperitoneal local anaesthetic for shoulder pain after day-case laparoscopy. Lancet 1991; 338: 1569-70.

18 Riedel HH, Semm K. The post-laparoscopic pain syndrome (author's syndrome) (German). Geburtshilfe Frauenheilkd 1980; 40: 635-43.

19 Beauregard L, Pomp A, Choiniere M. Severity and impact of pain after day-surgery. Can J Anaesth 1998; 45: 304-11.

20 Reuben SS, Connelly NR, Maciolek H. Postoperative analgesia with controlled-release oxycodone for outpatient anterior cruciate ligament surgery. Anesth Analg 1999; 88: 1286-91.

21 Band CJ, Band PR, Deschamps M, Besner JG, Coldman AJ. Human pharmacokinetic study of immediaterelease (codeine phosphate) and sustained-release (Codeine Contin) codeine. J Clin Pharmacol 1994; 34: 938-43.

22 Aldrete JA, Kroulik D. A postanesthetic recovery score. Anesth Analg 1970; 49: 924-34.

23 Aldrete JA. The post-anesthesia recovery score revisited (Letter). J Clin Anesth 1995; 7: 89-91.

24 Cleeland CS, Ryan KM. Pain assessment: global use of the brief pain inventory. Ann Acad Med Singapore 1994; 23: 129-38.

25 Kinnard P, Lirette R. Outpatient orthopedic surgery: a retrospective study of 1996 patients. Can J Surg 1991; 34: 363-6.

26 Fortier J, Chung F, Su J. Unanticipated admission after ambulatory surgery: a prospective study. Can J Anaesth 1998; 45: 612-9.

27 Jin FL, Chung F. Postoperative pain - a challenge for anaesthetists in ambulatory surgery. Can J Anaesth 1998; 45: 293-6.

28 Bisgaard T, Klarskov B, Rosenberg J, Keblet H. Factors determining convalescence after uncomplicated laparoscopic cholecystectoymy. Arch Surg 2001; 136; 917-21.

29 Sunshine A, Olson NZ, Colon A, et al. Analgesic efficacy of controlled-release oxycodone in postoperative pain. J Clin Pharmacol 1996; 36: 595-603.

30 Mandema JW, Kaiko RF, Oshlack B, Reder RF, Stanski $D R$. Characterization and validation of a pharmacokinetic model for controlled-release oxycodone. Br J Clin Pharmacol 1996; 42: 747-56.

31 Crews JC. Multimodal pain management strategies for office-based and ambulatory procedures. JAMA 2002; 288: 629-32. 